\title{
Críticas de Skinner e Merleau-Ponty à Causalidade
}

\author{
Henrique Mesquita Pompermaier* \\ Orcid.org/0000-0003-3002-6503
}

\begin{abstract}
Universidade federal do Rio Grande do Norte, Faculdade de Ciências da Saúde do Trairi,
Santa Cruz, RN, Brasil
\end{abstract}

\section{Resumo}

Encontra-se, tradicionalmente, uma forte identificação entre explicação e causa, tanto na filosofia, quanto na ciência e no senso comum. Contudo, revisões críticas instauradas no âmbito da filosofia da ciência, particularmente a partir do século XX, questionam essa identificação tácita, de modo que uma explicação científica não implica necessariamente em apontar causas. Exemplos dessa compreensão aplicados a discussões com relação a fenômenos psicológicos podem ser encontradas em diferentes tradições, como a fenomenologia-existencial de M. Merleau-Ponty, e o comportamentalismo radical de B. F. Skinner. Este trabalho busca salientar a crítica em relação ao pensamento causal, discutindo seu papel fundamental para a abordagem do comportamento como fenômeno com sentido próprio, como pretendido nessas duas perspectivas. Em ambas as abordagens, explicar não é encontrar as causas, mas descrever, a estrutura do comportamento, para Merleau-Ponty, ou as contingências de reforçamento, para Skinner. Nesse sentido, indica-se essa postura crítica como elemento favorecedor de possíveis aproximações e diálogos entre essas diferentes perspectivas.

Palavras-chave: Causalidade, explicação, Skinner, Merleau-Ponty.

\section{Skinner and Merleau-Ponty's Criticism of Causality}

\begin{abstract}
A strong connection between explaining phenomena and identifying causes is commonly observed not only in philosophical, but also in scientific and common sense discourse. Nonetheless, critical analyses conducted in philosophy of science, especially as of the twentieth century, questioned this tacit connection, to the effect that a scientific explanation does not necessarily imply identifying causes. Examples of this viewpoint applied to discussions of psychological phenomena can be found in various traditions, such as M. Merleau-Ponty's existential-phenomenology and B. F. Skinner's radical behaviorism. The present paper seeks to highlight the criticism of causal theories, discussing the fundamental contribution of such criticism to treating behavior as a phenomenon with its own sense, as was proposed in MerleauPonty and Skinner's approaches. Both approaches claim that explaining behavior does not signify identifying causes, but rather describing either the structure of behavior, according to Merleau-Ponty, or the contingencies of reinforcement, according to Skinner. Along these lines, we recommend such criticism as an element favoring potential closeness and dialogue between these different perspectives.
\end{abstract}

Keywords: Causality, explanation, Skinner, Merleau-Ponty.

* Endereço para correspondência: Rua Vila Trairi, s/n, Centro, Santa Cruz, RN, Brasil, 59.200-000. E-mail: henriquepompermaier@gmail.com.

No período de submissão e aceite deste artigo, o autor contou com apoio financeiro: Bolsa Fundação de Amparo à Pesquisa do Estado de São Paulo (FAPESP) de Doutorado, processo n 2013/25363-9. 


\section{Las criticas de Skinner y Merleau-Ponty a la causalidad}

\section{Resumen}

Observase tradicionalmente una identificación fuerte entre explicación y causas, tanto en la filosofía cuanto en la ciencia y el sentido común. Sin embargo, revisiones críticas desde la filosofía de la ciencia, sobre todo a partir del siglo XX, cuestionaron esta identificación tácita, por lo que una explicación científica no implica necesariamente apuntar causas. Ejemplos de esta comprensión aplicada a los debates sobre los fenómenos psicológicos pueden ser encontrados en diferentes tradiciones, como la fenomenología existencial M. Merleau-Ponty, y el conductismo radical de B.F. Skinner. En este trabajo se pretende dar a conocer la crítica del pensamiento causal, discutiendo su papel clave en el enfoque de la conducta como un fenómeno con su propio sentido, como pretendido en esas dos perspectivas. En ambos enfoques, explicar no es encontrar las causas, sino que describir la estructura de la conducta, para Merleau-Ponty, o las contingencias de reforzamiento, para Skinner. En este sentido, se indica esta posición crítica como elemento favorecedor de aproximaciones posibles y diálogos entre estas diferentes perspectivas.

Palabras clave: Causalidad, explicación, Skinner, Merleau-Ponty.

\section{Aproximações entre a Fenomenologia de Merleau-Ponty e o Comportamentalismo de Skinner}

A proposição de diálogos entre a fenomenologia e o comportamentalismo é controversa, mas encontra indicações favoráveis (e.g. Abib, 1988; Kvale \& Grenness, 1967; Pérez-Alvarez \& Sass, 2008; Wann, 1964). O livro Behaviorism and Phenomenology: Contrasting Bases for Modern Psychology (Wann, 1964) configura-se como um dos trabalhos mais conhecidos e celebrados em relação a esse debate. Organizado a partir de um simpósio realizado em 1963 na Universidade de Rice, a obra congrega os textos relativos às falas de psicólogos de orientação fenomenológica (C. Rogers e R. B. McLeod), comportamentalista radical (B. F. Skinner) e filósofos da ciência (N. Malcom e M. Scriven). A partir dessas falas e do livro publicado, ao menos dois artigos (Day, 1969; Giorgi, 1975) foram dedicados ao tema em revistas da área analítico-comportamental, comentando sobre as possibilidades de diálogo e conciliação entre Fenomenologia e Análise do Comportamento.

De maneira geral, entretanto, os registros das falas do simpósio, bem como os artigos dos comentadores apontados, apresentam poucas considerações que demonstrem uma compreensão pertinente de parte a parte acerca dos fun- damentos de cada proposta. Mais que isso, para Kvale e Grenness (1967), a versão norte-americana da fenomenologia-existencial colocada no debate, desenvolvida primordialmente no contexto clínico, apresentaria interpretações marcadamente idealistas, subjetivistas e voluntaristas, incompatíveis com a compreensão indicada nas propostas fenomenológico-existenciais de J. P. Sartre e M. Merleau-Ponty, por exemplo. Desse modo, as oposições da versão norte-americana ao comportamentalismo radical não se estendem, ou não se constituem na relação deste último com a vertente europeia da fenomenologia. Como comenta Abib (1988) "O debate realizado nos Estados Unidos acerca do Behaviorismo e da fenomenologia (editado por T. W. Wann em 1964, sob o título 'Behaviorism and Phenomenology') e que contou com a participação de Skinner, deixou a desejar" (p. 426).

Divergindo das considerações apresentadas no referido simpósio, Kvale e Grenness (1967) salientam a proximidade e fecundidade do confronto entre as proposições metapsicológicas encontradas nas obras de Merleau-Ponty (e.g., 1942/2006, 1945/1994) e de Sartre (e.g., 1939/1948, 1940/1972) com aquelas encontradas nas obras de Skinner (e.g., 1957, 1953/1965, 1974/1976). Os principais elementos que marcariam a proximidade entre as posições desses autores seriam: (a) a relação entre a compreensão 
do operante e a noção de direcionalidade e ação no mundo; (b) as críticas ao subjetivismo e ao mentalismo; bem como o decorrente (c) questionamento e propostas de superação do dualismo instaurado pelas tradições mentalista e fisicalista na psicologia.

O desenvolvimento dessas proposições metapsicológicas passam, em grande medida, pela compreensão do comportamento como objeto de estudo para abordagem dos fenômenos psicológicos. Vastamente reconhecida na proposta comportamentalista skinneriana, tal perspectiva pode ser também encontrada na proposta fenomenológica-existencial de Sartre e Merleau-Ponty. Como salientam Kvale e Grenness (1967), "Enquanto Husserl e outros fenomenólogos antigos focaram a intencionalidade da consciência, Merleau-Ponty e Sartre destacaram a intencionalidade do comportamento - relacionalidade [relatedness] básica do homem para com o mundo" (p. 137).

Ao considerar a compreensão do campo psicológico como campo comportamental, Merleau-Ponty (1942/2006) argumenta que as correntes psicológicas de cunho comportamentalista do início do século XX (e.g. reflexologia e behaviorismo watsoniano) teriam sua potencialidade prejudicada pelo comprometimento com fundamentos filosóficos problemáticos, como o realismo, o atomismo e o pensamento causal.

Paralelamente, apresentando a proposta de elaboração de uma ciência do comportamento a partir da investigação experimental desse objeto em seu próprio direito e domínio, Skinner analisa criticamente a tradição da reflexologia e do behaviorismo clássico. $\mathrm{O}$ autor argumenta que apesar de representarem um avanço importante, ao colocar a atenção das discussões e estudos dos fenômenos psicológicos em "dimensões físicas" (Skinner, 1938/1966, p. 4), essas abordagens tiveram também o efeito negativo de desencorajar um "ataque descritivo" sobre o comportamento propriamente dito, dada sua ênfase em uma explicação causal mecânico-linear, atribuindo ao sistema nervoso um papel de "entidade controladora" (Skinner, 1938/1966, p. 4).

Frente a esse quadro, o presente trabalho visa apresentar e discutir a consideração da críti- ca e superação do pensamento causal como mais um item à relação de proposições metapsicológicas comuns entre a perspectiva fenomenológica-existencial europeia e a abordagem comportamentalista radical (Kvale \& Grenness, 1967). A partir da obra de Merleau-Ponty (1942/2006) dedicada ao exame da noção de comportamento (A Estrutura do Comportamento), e de textos de Skinner (1957, 1931/1961, 1953/1965, 1938/1966, 1981/1984) pertinentes à questão da explicação do comportamento, apresentamos uma análise da crítica à lógica causal desenvolvida por esses autores em suas discussões acerca da abordagem dos fenômenos psicológicos. Para isso, apresentamos uma breve discussão sobre a questão da causalidade na filosofia da ciência e na psicologia, de modo a estabelecer uma definição de explicação causal a ser usada na discussão das propostas de Merleau-Ponty e Skinner.

\section{Explicação e Causalidade na Filosofia da Ciência}

A identificação entre explicação e causa é longa e forte na história da filosofia. Já é indicada em Platão (essências que explicam as aparências); estabelecida como possibilidade para o "conhecimento científico" em Aristóteles; e apresentada como condição para qualquer conhecimento em Kant (Laurenti \& Lopes, 2008). De modo geral, essa identificação foi pouco criticada ao longo da história da filosofia, até o século XX. Questões foram levantadas acerca de suas condições, tipos, características e definições (Laurenti \& Lopes, 2008), mas raramente foram colocadas em relação à sua pertinência ou coerência, de modo a vislumbrar a possibilidade de sua exclusão total. Dessa forma, tradicionalmente, tanto na filosofia quanto na ciência e no senso comum, explicar foi entendido como encontrar as causas.

Entretanto, junto às revisões críticas da ciência, em seus fundamentos filosóficos e práti$\cos$, mais fortemente instauradas a partir do século XX, encontram-se indagações que colocam em xeque o consenso acerca da identificação entre explicação científica e causalidade (Laurenti, 2009). Mach (1886/1959), por exemplo, 
argumenta que a explicação causal seria uma forma muito limitada e imprecisa para abordar as relações de interdependência entre eventos na natureza. Como alternativa, o autor propõe uma compreensão funcional para a relação entre eventos, noção que acreditava ter maior precisão e flexibilidade.

Outra crítica ao modelo causal de explicação científica é apresentada por Hempel (1965). $\mathrm{O}$ autor argumenta que uma explicação científica não implica necessariamente em apontar causas, como pode ser observado nas explicações pautadas em leis taxonômicas, ou em leis estatísticas. Por outro lado, a indicação de causas não é encontrada exclusivamente em explicações científicas. Explicações mitológicas ou religiosas muitas vezes constroem-se como um discurso causal. Para o autor, portanto, leis causais seriam uma das leis da explicação científica, mas não a única.

De modo semelhante, Bunge (1959/1963) argumenta que ainda que a explicação causal seja apontada como exemplo paradigmático de explicação científica, ela não seria a única forma de responder aos "porquês" desse tipo de investigação. Comentando sobre essa perspectiva, Laurenti e Lopes (2008, p. 384) afirmam: "Há outras categorias não-causais de explicação da realidade (por exemplo: estatísticas, dialéticas, teleológicas e funcionais), que expressam formas mais complexas e dinâmicas de relação entre processos e eventos". Segundo Bunge, do ponto de vista ontológico, o discurso da causalidade aplicar-se-ia apenas aos casos de relações lineares, unilaterais e necessárias.

Pode-se discutir que tais críticas apresentadas à causalidade não são aplicáveis a todas as concepções do termo. Contudo, a partir delas, compreende-se também que não se pode assumir que todas as relações de dependência entre eventos, estabelecidas em explicações científicas, são causais (ainda que de diferentes tipos). Do contrário, a noção de relação (de dependência) causal, seria tautológica e sem sentido: "o emprego do termo causal só faz sentido se admitirmos que há relações de dependência não-causais" (Laurenti \& Lopes, 2008, p. 385).
Para aprofundar a discussão do tema, portanto, é preciso assumir (a) que há relações não-causais de dependência entre eventos, e (b) uma definição específica de causalidade, como balizadora das discussões e críticas a serem lançadas. Neste trabalho, a exemplo de Laurenti e Lopes (2008), tomamos por base a definição de causalidade proposta por Bunge (1959/1963).

Para Bunge (1959/1963), seriam princípios pertinentes à noção de causalidade:

1. A condicionalidade (a ocorrência do evento depende da ocorrência de determinadas condições);

2. A unicidade do elo causal (correspondência "um pra um" entre causa e efeito - um evento só pode ser causa de um único efeito, e vice-versa);

3. A conexão necessária entre causa e efeito (um evento é causa de outro: sempre que ele ocorrer, o outro invariavelmente ocorrerá);

4. A dependência unilateral (a causa é agente, e o efeito é passivo na relação entre os eventos); e

5. A conexão genética (a causa é geradora; o efeito é produto - explicar a origem de algo implica em indicar sua causa).

\section{Causalidade e Ciência Psicológica}

Sob o espectro da tradição Positivista e dos avanços e conquistas tecnológicas nas ditas "ciências duras" nos séculos XVIII e XIX, o desafio colocado às primeiras propostas de construção de uma Psicologia científica era de como delimitar seu campo de análise e definir seu objeto de estudo de forma compatível aos cânones de cientificidade, tais como observabilidade direta e mensuração. Como tratar de forma científica algo que desde as primeiras elaborações sobre as possibilidades de conhecimento (que culminaram de alguma forma no pensamento científico organizado) vinha sendo separado, excluído ou isolado como de natureza distinta, e que, não obstante, ainda era por muitos considerada a fonte dos erros e desvios, um mal a ser evitado ou contornado? Em suma, como construir logos sobre a psyché? 
Alguns movimentos nesse sentido buscaram no oceano psíquico ilhas seguras - fenômenos que pudessem ser quantificados e mensurados utilizando-se de métodos e instrumental próximos aos das ciências em curso, comumente reunidas sob o rótulo de "ciências naturais". Junto a esses métodos e instrumental, foram importadas também perspectivas e fundamentos filosóficos, como compreensões atomistas, mecanicistas e realistas.

Importou-se também a compreensão da tarefa da ciência - explicar o mundo encontrando as causas dos fenômenos. Tratava-se, pois, da tentativa de aplicar aos fenômenos psicológicos a lógica explicativa usada na compreensão dos objetos. Se o conhecimento dos objetos podia se dar por sua decomposição em partes menores, elementares, o mesmo deveria se dar com os processos presentes na relação dos organismos com o mundo. A partir dessa compreensão, as propostas científicas em psicologia definiam seus fenômenos como uma composição partes extra partes, buscando descobrir sob quais leis determináveis um elemento psíquico (determinado e passível de independência) acionava o funcionamento do elemento seguinte, que por sua vez acionava o seguinte, numa cadeia de causas e efeitos - uma cadeia causal - que compunha o fenômeno psicológico.

Entre os diferentes candidatos a objeto de estudo, como dados da consciência e sensações elementares, os movimentos dos organismos foram tomados na esteira de uma longa tradição de trabalho no âmbito das ciências fisiológicas, que já havia lançado as bases para uma teoria do comportamento reflexo (Pessotti, 1982). Herdeiro dessa tradição, o Behaviorismo propunha uma reconfiguração na compreensão dos fenômenos psíquicos. Era preciso garimpar entre esses fenômenos aqueles passíveis de uma descrição em termos de instâncias físicas. As explicações se dariam por meio da decomposição desses fenômenos em relações de associação entre estímulos (eventos físicos no mundo) e respostas (eventos comportamentais, reações fisiológicas dos organismos).

Contra essa redução do fenômeno psíquico ao físico, outras propostas fincavam base no polo oposto - o psíquico teria uma natureza distinta, mental, inacessível ou acessível apenas indiretamente às pretensões das ciências naturais. Como afirma Japiassu (1977), o conhecimento acerca do humano parecia oscilar

... entre um conhecimento organicista e materialista do ser corporal e biológico do homem, e um saber espiritualista da vida psíquica, intelectual e moral da 'alma' humana, ligando os dois de modo mais ou menos bastardo no plano da objetividade. (p. 24)

É sobre esse contexto que se debruçam as obras iniciais de M. Merleau-Ponty (1942/2006, $1945 / 1994)$, ao analisar criticamente as compreensões sobre o comportamento e a percepção. É diante desse impasse também, porém vivenciado no contexto da própria tradição comportamentalista, que se desenvolve a abordagem analítico-comportamental de B. F. Skinner (e.g. 1953/1965, 1971, 1974/1976).

Como comenta Hidalgo (2017), apesar dos objetivos distintos, Skinner partilha com Merleau-Ponty não apenas o desenvolvimento de reflexões "acerca do estatuto filosófico da noção de comportamento", mas também a sensibilidade "a questões teóricas semelhantes como, por exemplo, a insuficiência dos princípios da reflexologia clássica na explicação do comportamento", propondo-se igualmente a elaborar uma "noção de comportamento em seu terreno próprio (irredutível, portanto, à fisiologia)" (Hidalgo, 2017, p. 161). Nessa direção, encontramos tanto em Merleau-Ponty quanto em Skinner o encaminhamento de uma compreensão para o comportamento que, buscando afastar os fantasmas das abordagens intelectualistas (mentalismo), passa pela crítica às insuficiências e limitações da reflexologia e das teorias do condicionamento do início do século XX. Dentre essas críticas, destacamos nas seções a seguir, aquelas pertinentes ao modelo explicativo causal.

\section{A Crítica de Merleau-Ponty à Causalidade Linear na Explicação do Comportamento}

A perspectiva filosófica merleau-pontyana de superação das dicotomias da metafísica clás- 
sica (subjetivo-objetivo; interno-externo; mente-corpo) para compreensão do fenômeno humano encontrou terreno fértil na psicologia. Como apontam Verissimo e Furlan (2007), desde sua primeira grande obra, (A Estrutura do Comportamento) Merleau-Ponty "inicia um debate rigoroso, crítico e sistemático com o realismo presente na psicologia científica" (Verissimo \& Furlan, 2007, p. 334). Recorrendo a interpretações e argumentações presentes na obra de Goldstein, Koffka e Köhler, Merleau-Ponty (1942/2006) destaca a noção de forma (Gestalt) como possibilidade de superação da perspectiva objetivista e reducionista das teorias do reflexo (e.g., Sherington, Pavlov, Watson), sem, contudo, abandonar o campo empírico em favor de asserções idealistas ou racionalistas.

O reconhecimento do fracasso da proposta fisicalista da psicologia (objetiva) não representaria a indicação de um retorno a perspectivas mentalistas (idealista, subjetivista). Nesse sentido, Merleau-Ponty (1942/2006) defende a manutenção da noção de comportamento como fundamental para abordagem dos fenômenos psicológicos. Alcançada diretamente e passível de descrição objetiva, a noção de comportamento, "tomada nela mesma", seria o caminho para a redefinição do "psiquismo" e do "fisiológico", de modo a superar as dicotomias clássicas comumente a eles relacionadas (Merleau-Ponty, 1942/2006, p. 3).

Para Merleau-Ponty (1942/2006), a compreensão encaminhada pela tradição do reflexo na psicologia considerava o organismo como uma "massa material "partes extra partes" (p. 2 ), cujas condutas realizar-se-iam a partir de conexões pré-estabelecidas. Os fenômenos eram entendidos como conjunções de elementos independentes, e sua explicação se dava pela descrição de relações exteriores e mecânicas. O trabalho explicativo em relação ao comportamento, se daria pela determinação das dependências lineares entre estímulos e receptores, e entre receptores e efetores. O comportamento seria composto por unidades que se associam e se dissociam de acordo com leis relativas a propriedades físicas dos elementos envolvidos (e.g., modalidade sensorial, intensidade, localização, frequência, duração). Nessa perspectiva, a excitação proveniente dos estímulos seria a causa do comportamento (efeito), "no sentido empirista de um antecedente constante e incondicionado" (Merleau-Ponty, 1942/2006, p. 8). O organismo, passivo, executaria o que lhe era prescrito pela excitação.

No quadro apresentado pelas teorias clássicas do reflexo os fenômenos psicológicos seriam reduzidos a comportamentos reflexos, tomados como fenômenos longitudinais: operações de agentes físicos ou químicos determinados sobre um receptor específico, provocando uma resposta determinada. Para Merleau-Ponty (1942/2006), uma das fontes de dificuldades e da insuficiência da proposta behaviorista seria justamente a tentativa de preservar na compreensão da aprendizagem a ideia dos fenômenos como associação entre realidades (estímulo real e movimento real), que, não obstante, permaneciam intactas a essa associação.

A crítica de Merleau-Ponty (1942/2006) às propostas da reflexologia e do Behaviorismo, é feita em grande medida com base nos argumentos desenvolvidos pelos psicólogos da Gestalt. Acompanhando as análises e discussões de autores como Koffka $(1925,1935)$ e Köhler (1927, 1930), Merleau-Ponty destaca como o quadro composto pelas teorias do reflexo não resistia a um exame dos próprios dados oferecidos pela psicologia experimental, tendo de recorrer constantemente a postulados ad hoc, em geral fora do campo comportamental, para tentar ainda construir uma interpretação inteligível dessa associação.

Tanto em pesquisas envolvendo humanos, como em pesquisas com não-humanos, os autores da "escola de Berlim" mostram que a disposição de um mesmo elemento em relação aos demais altera a forma como o organismo interage ou se relaciona com ele. Um estímulo nunca é apreendido isoladamente, em suas partes reais, mas sempre em um contexto, uma situação. E uma situação que em nada ganha, para a compreensão do fenômeno, com a descrição de suas propriedades reais, do estímulo "em si", mas sim da estrutura que conforma com a conduta: "Já que a decomposição em partes reais nunca pode ter 
fim, nunca é como realidade física individual que o estímulo se torna reflexógeno, é sempre como estrutura" (Merleau-Ponty, 1942/2006, p. 162).

Como exemplos, Merleau-Ponty (1942/ 2006) aponta experimentos utilizando a figura de Jastrow e o uso de iluminações ou composições com cores distintas ${ }^{1}$. Os resultados desses estudos mostrariam que o excitante não pode ser concebido como um estímulo discreto e causador, devendo ser tomado como uma situação, um contexto, ou ainda, uma estrutura:

O verdadeiro excitante das reações condicionadas não é nem um som, nem um objeto considerados como indivíduos, nem uma reunião de sons ou objetos considerados como conjuntos ao mesmo tempo individuais e confusos, mas antes a distribuição dos sons no tempo, sua sequência melódica, as reações de grandeza dos objetos; em geral: a estrutura precisa da situação. (Merleau-Ponty, 1942/2006, pp. 83-84)

Apesar dos avanços na constituição de um pensamento estrutural contra o pensamento analítico que dominava as teorias do reflexo, Merleau-Ponty (1942/2006) argumenta que a Gestalttheorie recai na armadilha do pensamento polarizado de uma "filosofia da substância", como se precisasse escolher entre encontrar seus elementos em uma substância material ou uma substância imaterial. Pendendo novamente para a vertente fisicalista como defesa e garantia de cientificidade, a teoria da Gestalt acaba por tratar a forma como coisa tentando novamente fazer da ordem física "o fundamento real do comportamento" e da "estrutura perceptiva"

\footnotetext{
Merleau-Ponty discute alguns experimentos apresentados por Köhler em que animais eram treinados a escolher a menor entre duas figuras, ou uma determinada cor, ou ainda um determinado gradiente de cor, de modo a obter comida em seguida a cada resposta correta. Quando colocados diante de duas figuras idênticas, mas dispostas de modo que uma aparenta ser menor que a outra, ou de discos com cores idênticas, mas sob condições de iluminação de modo a aparentarem cores ou gradiente distintos, os animais escolhiam sistematicamente a figura que aparece à percepção humana como menor, ou com a cor ou gradiente treinado.
}

(Merleau-Ponty, 1942/2006, p. 225), ou seja, fazer das estruturas físicas a causa das estruturas percebidas. Combatendo a reificação das concepções atomistas, a teoria da Gestalt acaba por recorrer a uma reificação das formas ou estruturas, comprometendo-se com os mesmos fundamentos problemáticos das teorias do reflexo por ela criticadas (Merleau-Ponty, 1942/2006).

Como aponta Verissimo (2012), para Merleau-Ponty, é o sentido vivo, e não psicofísico, da noção de estrutura que está em jogo. É na reordenação da relação do organismo com o meio, ou ainda, no exame dessa ordenação no campo vital e humano, que a psicologia pode encontrar o sentido do comportamento, e não na reprodução desajeitada da ordem do campo físico, como buscavam as teorias do reflexo. Uma vez que as relações estabelecidas entre o indivíduo e o mundo são orientadas segundo a unidade significativa operada pelo organismo no meio, e que essa unidade significativa só é apreendida no mundo percebido, "O percebido seria explicável apenas pelo próprio percebido, e não por processos fisiológicos" (Merleau-Ponty, 1942/2006, p. 145). Trata-se de radicalizar a compreensão estrutural em uma verdadeira "filosofia da forma" (Merleau-Ponty, 1942/2006, p. 206), de modo a compreender o comportamento como "uma ligação dialética de sentido entre o organismo e o meio, relação de reciprocidade e interatividade" (Verissimo \& Furlan, 2007, p. 336).

Para Merleau-Ponty (1942/2006), portanto, o comportamento implica uma relação dialética, de reciprocidade, interatividade e ajustamento mútuo entre o organismo e $s^{2} u^{2}$ ambiente. Dessa forma, o método de análise real e de explicação causal, pertinente ao modo como as perspectivas fiscalistas tentavam estruturar a associação entre os elementos das ações, é estéril à tentativa de construção de uma compreensão do comporta-

2 Destaca-se aqui o pronome possessivo a fim de explicitar que, nessa perspectiva, o organismo não se relaciona com "qualquer" ambiente, com um ambiente real ou objetivo, mas sim com um ambiente já constituído por essa relação, ou seja, dependente dela, dependente do organismo, portanto, seu ambiente. 
mento em seu próprio campo. De uma maneira bastante próxima à encontrada na definição de Bunge (1959/1963) para a explicação causal, encontramos em Merleau-Ponty a caracterização do modelo causal implicado na teoria do reflexo para a explicação do comportamento:

Uma ação mecânica, quer tomemos a palavra no sentido restrito, quer no sentido amplo, é aquela em que a causa e o efeito são decomponíveis em elementos reais que se correspondem um a um [unicidade do elo causal]. Nas ações elementares, a dependência é de mão única [dependência unilateral], a causa é condição necessária e suficiente do efeito [conexão necessária] considerado na sua existência e natureza [conexão genética] e, mesmo quando se fala de ação recíproca entre dois termos, esta se deixa reduzir a uma série de determinações de mão única. (Merleau-Ponty, 1942/2006, p. 250)

A defesa da noção de estrutura como fundamento para ordenação da relação entre os organismos e o mundo mostra-se incompatível com a compreensão mecanicista do comportamento e, consequentemente, interdita sua abordagem a partir do modelo explicativo causal. Nessa mesma direção, em uma nota na introdução d' $A E S$ trutura do Comportamento, Merleau-Ponty destaca que a noção de comportamento, tal como proposta inicialmente por Watson, só "poderia receber seu estatuto filosófico se o pensamento causal ou mecânico fosse abandonado em prol do pensamento dialético" (Merleau-Ponty, 1942/2006 p. 4, nota 3). A compreensão do comportamento se faz possível, portanto, na medida em que "renunciamos tanto ao realismo mecanicista quanto ao realismo finalista, ou seja, a todas as formas de pensamento causal [ênfase adicionada]" (Merleau-Ponty, 1942/2006, p. 76).

A significação do comportamento estaria na síntese, não na análise. Em lugar do pensamento causal, Merleau-Ponty (1942/2006) indica que a abordagem do comportamento deveria ser guiada por uma compreensão em termos de função ou sentido: "Vimos, por exemplo, que duas excitações díspares são fundidas na visão se exercem a mesma função [ênfase adicionada] nas duas regiões coloridas, ou seja, a de 'ponto sobre um fundo homogêneo" (Merleau-Ponty, 1942/2006, p. 145). Ou ainda:

Não é porque duas excitações retinianas estão inseridas no mesmo circuito associativo que seus correspondentes psíquicos recebem a mesma função no espaço percebido; é inversamente esta função comum que os designa para serem ligados por um circuito associativo. A própria coordenação aparece como resultado: o efeito de um fenômeno de estrutura ou de "forma" (Merleau-Ponty, 1942/2006, p. 125)

Tomando a definição da causalidade em Bunge (1959/1963), podemos encontrar na proposta crítica de Merleau-Ponty (1942/2006) a superação de cada uma de suas características:

Ao contrário, como vimos, os estímulos físicos só agem no organismo nele suscitando uma resposta global que varia qualitativamente quando eles variam quantitativamente [contra a "unicidade do elo causal"]; exercem, com relação a ele, mais o papel de ocasiões que de causas [contra a "conexão necessária"]; a reação depende, mais que das propriedades materiais dos estímulos, de seu significado vital. Assim, entre as variáveis das quais depende efetivamente a conduta e esta própria conduta, aparece uma relação de sentido, uma relação intrínseca [contra a "conexão genética"]. Não podemos designar um momento em que o mundo age sobre o organismo, já que o efeito mesmo dessa "ação" exprime a lei interior do organismo [contra a "dependência unilateral"]. Ao mesmo tempo que a exterioridade mútua dos estímulos, também a exterioridade mútua entre o organismo e aquilo que o rodeia se acha superada. Esses dois termos definidos isoladamente devem pois ser substituídos por dois correlatos, o "meio" e a "aptidão", que são como dois polos do comportamento e participam de uma mesma estrutura. (pp. 250-251)

Restaria apenas o caráter de condicionalidade, para o qual, na verdade, encontra-se uma indicação positiva. Contudo, a indicação de con- 
dições determinadas das quais um evento dependeria não reintroduz, de forma alguma, o pensamento causal atomista. Para Merleau-Ponty (1945/2006), tal indicação reflete apenas a descrição da ordenação do comportamento, e "não tem sentido se o transformamos em um problema de causalidade" (p. 74). A explicação do campo comportamental não é a busca pela causa do comportamento - os eventos simplesmente ocorrem quando as condições necessárias estão presentes (Merleau-Ponty, 1945/2006).

Buscando oferecer uma compreensão para o comportamento, pode-se dizer, em uma abordagem merleau-pontyana, que ele possui sentido, direção, intencionalidade - "O comportamento intencional é direcionado para o mundo, ele age sobre o mundo e revela este mundo para o homem" (Kvale \& Grenness, 1967, p. 137). Mas não se pode dizer que ele que possui uma causa (no sentido forte do termo). Ao menos não a partir da definição apresentada por Bunge (1959/1963). Não há um agente externo que conduza ou obrigue o corpo a agir; tampouco há qualquer necessidade de recorrer a um agente interno como motor da ação. Nem há espaço para que esse agente interno concentre os sentidos e intenções - eles já são próprios ao comportamento, compreendido como relação dialética entre organismo e mundo.

Dessa forma, a crítica à noção de causalidade linear que sustenta a teoria clássica do reflexo e suas derivações na fisiologia e na psicologia, pode ser entendida como um dos aspectos chave para a discussão da noção comportamento e para os questionamentos colocados por Merleau-Ponty à Psicologia em relação a "seus métodos, seus alcances e a noção de ser que dela emerge" (Verissimo \& Furlan, 2007, p. 332). Decorre dessa compreensão que, na perspectiva proposta por Merleau-Ponty n'A Estrutura do Comportamento, explicar o comportamento não significa apontar suas causas, como se essas the fossem alheias (tal como na teoria clássica do reflexo), mas sim descrever "a constituição de 'formas' ou de estruturas funcionais" (Merleau-Ponty, 1942/2006, p. 139).

\section{A Proposta Skinneriana de Explicação do Comportamento e a Crítica à Causalidade}

A identificação entre o nome de B. F. Skinner e a proposta behaviorista clássica é uma confusão recorrente e fonte de incompreensões e preconceitos em relação à proposta do psicólogo estadunidense (e.g., Carrara, 2005; Chiesa, 1994). Influenciado pela tradição behaviorista, Skinner (1931/1961, 1938/1966) explora em seus primeiros trabalhos a explicação reflexa do comportamento, porém já vislumbrando distinções entre tipos de respostas do organismo, fato que leva o autor a propor a construção de um tipo diferente não apenas de conceito de comportamento, mas de interpretação comportamental - a teoria operante. Salientando as diferenças em relação às teorias do reflexo, alguns autores (e.g. Abib, 2004; Chiesa, 1994) questionam a pertinência da identificação da proposta skinneriana sob a mesma nomenclatura (implicando na compreensão de pertencimento a uma mesma tradição) que propostas como as de $\mathrm{Pa}$ vlov e Watson.

Entre as diferenças mais marcantes da perspectiva comportamentalista radical de Skinner em relação às propostas tradicionais da reflexologia e do behaviorismo, ressalta-se a ênfase na relação da ação do organismo com o ambiente subsequente à ação. São as chamadas consequências do comportamento, reforçadoras quando seguidas de um aumento na frequência das respostas, punitivas se seguidas de uma diminuição, caracterizando o novo tipo de comportamento, operante, que marcam a possibilidade de uma proposta comportamental voltada para o "campo do propósito e da intenção" (Skinner, 1938/1966, p. xii, 1974/1976, p. 55).

Diferente da proposta behaviorista tradicional, na abordagem skinneriana o ambiente tem um papel selecionador das ações, e não causal. Não há "aguilhão" - "a noção de reflexo é para ser esvaziada de qualquer conotação de "empurrão' ativo do estímulo" (Skinner, 1938/1966, p. 21). O ambiente atua como contexto, antecedente e subsequente, a interagir com o organismo - "Os homens agem sobre o mundo, modificam- 
-no, e, por sua vez, são modificados pelas consequências de sua ação" (Skinner, 1957, p. 1).

Reconhecidamente influenciado pelo trabalho de E. Mach, Skinner (1931/1961) afirma já em um de seus primeiros trabalhos que em sua proposta de ciência do comportamento "a noção de causalidade é substituída pela de função" (p. 338). Desse modo, para o comportamentalismo radical

Uma "causa" torna-se uma "mudança na variável independente" e um "efeito" uma "mudança na variável dependente". A antiga "conexão causa-e-efeito" torna-se uma "relação funcional". Os novos termos não sugerem como uma causa produz seu efeito; mas simplesmente que eventos diferentes tendem a ocorrer juntos em uma certa ordem. (Skinner, 1953/1965, p. 23)

Outro aspecto marcante da proposta skinneriana, que também pode ser atribuído à influência da obra de Mach e, principalmente, ao pensamento darwinista, refere-se a seu caráter selecionista. Skinner (1981/1984) denomina seu sistema explicativo ${ }^{3}$ como "modelo de seleção pelas consequências". A explicação do comportamento humano dar-se-ia em três níveis: filogenético, ontogenético e cultural. Em todos eles o ambiente não causa uma resposta, mas altera a probabilidade de ocorrências futuras, isto é, seleciona e fortalece (no sentido de "tonar mais provável") a correlação de uma classe de estímulos com uma classe de respostas, seja ela em nível da sobrevivência da espécie, da persistência de uma conduta ou da manutenção de uma prática cultural. Nesse sentido, diz-se que uma resposta foi selecionada quando tal resposta, em um determinado contexto, opera sobre o ambiente, de modo que uma alteração nesse

3 No referido texto - "Selection by consequences" - Skinner (1981/1984) afirma que o modelo de seleção pelas consequências é o "modelo causal" do behaviorismo radical. Como será indicado na seção a seguir, pode-se encontrar aqui um exemplo da confusão e inconsistência presente na obra do autor em relação à noção de causa, que, neste caso, parece indicar a noção de "modelo explicativo". ambiente que a segue aumenta a probabilidade de ocorrência dessa relação - contexto antecedente-resposta-contexto subsequente - em oportunidades futuras.

Porém, apesar de afirmar claramente a compreensão da necessidade do abandono do modelo explicativo causal (Skinner, 1931/1961, 1953/1965), e construir sua proposta pautada em uma noção de comportamento incompatível com essa lógica, há momentos na obra de Skinner em que o autor faz uso do termo "causa" (e suas variações) como equivalente para "explicação" (Skinner, 1981/1984), ou ainda, para expressar-se sobre a relação entre eventos na relação comportamental (e.g., Skinner 19694 $1985^{5}$ ). A presença confusa de tais indicações, entretanto, pode ser minimizada pela ênfase na compreensão funcional e selecionista do comportamento - caminho apontado para o abandono do modelo de explicação causal. Endossando essa perspectiva, Laurenti e Lopes (2008) confrontam as categorias apontadas por Bunge (1959/1963) como definidoras da lógica causal com indicações da abordagem skinneriana.

Em relação à "unicidade do elo causa", por exemplo, observa-se que a explicação do comportamento skinneriana em termos de variáveis dependente e independente não apresenta essa característica. Uma variável independente pode estar relacionada a diferentes eventos, ou ainda, funcionar de diferentes maneiras, assumir diferentes funções. O mesmo vale para variáveis dependentes, que podem estar relacionadas a diferentes eventos - podem ser função de distintas variáveis.

De modo semelhante, a condição de "conexão necessária" também não é encontrada na proposta skinneriana, uma vez que a variável dependente refere-se à probabilidade da ocorrência de uma dada resposta, e não à resposta em si. Ou seja, a presença da variável independente não

4 "Mas feelings são na melhor das hipóteses acompanhamento, não causas" (Skinner, 1969, p. 257).

5 "Se nós assumirmos que o que é sentido são produtos colaterais das causas do comportamento, os sentimentos podem ser dicas úteis destas causas" (Skinner, 1985, p. 300). 
implica em alteração necessária de uma determinada variável dependente - o que se observa é a alteração na probabilidade de que essa resposta (variável dependente) ocorra. A relação entre as variáveis em questão "é flexível e continuamente gradual” (Skinner, 1953/1965, p. 110).

A proposta skinneriana também não se coaduna com a "dependência unilateral" implicada na noção de causa. Os elementos envolvidos organismo e ambiente - apresentam uma relação recursiva, e não unilateral. Ambos atuam um sobre o outro, influenciando-se mutuamente, determinando, inclusive, sua definição: "Nenhum dos termos pode ser definido em suas propriedades essenciais sem o outro" (Skinner, 1938/1966, p. 9). Não há ênfase em nenhum dos polos, mas sim na relação.

Por fim, não se encontra na proposta skinneriana uma "conexão genética" entre a causa (geradora) e o efeito (produto). No comportamentalismo radical, a compreensão do comportamento se dá em termos da explicitação de uma ordem em que os elementos estão regularmente relacionados, sem que essa ordem implique em afirmar que o evento anterior gera, ou ainda, causa o posterior (Skinner, 1953/1965).

Em relação ao elemento de condicionalidade da definição de Bunge (1959/1963), observa-se uma indicação positiva na proposta skinneriana, tal como apontado no caso de Merleau-Ponty. E como indicado para a proposta merleau-pontyana, a presença dessa característica não implica no compromisso com a perspectiva causal. A condicionalidade inscreve-se na proposta de Skinner como caracterização da relação estabelecida entre ação e ambiente a partir do processo de reforçamento - ela denota o fato de que tal relação "não existia até que a operação de reforçamento tenha sido realizada" (Skinner, 1938/1966, p. 61). Nesse sentido, Skinner aponta que o termo francês conditionnel - "condicional" - representaria melhor o significado pretendido com a utilização do termo em inglês conditioned - "condicionado" - na caracterização do comportamento.

Como concluem Laurenti e Lopes (2008) é possível argumentar que há na abordagem analítico-comportamental de Skinner um forte direcionamento à superação do pensamento causal, ao menos tal como definido por Bunge (1959/1963). Desse modo, encontramos também em Skinner a superação da causalidade como um traço característico e distintivo de sua proposta para compreensão do comportamento.

\section{Considerações Finais}

Explorando a indicação do comportamento como conceito fundamental na primeira obra de Merleau-Ponty (1942/2006), dedicada ao tema, encontramos a centralidade da crítica e superação do modo de explicação causal. A (re)ordenação desse conceito a partir da noção de forma passa necessariamente pelo abandono da visão da relação entre organismo e mundo como constituída em uma cadeia causal de eventos mecânicos discretos.

De modo semelhante, pode-se constatar também que, diferenciando-se da tradição do reflexo, a proposição skinneriana da teoria do operante marca uma compreensão relacional do comportamento. Considerando que as respostas do organismo e os estímulos do ambiente articulam-se de modo funcional, não faz sentido falar em causas do comportamento. $\mathrm{O}$ ambiente não provoca o organismo a se comportar, mas seleciona o comportamento por meio de suas consequências, fortalecendo o entrelaçamento entre uma classe de estímulo e uma classe de respostas, funcionalmente determinadas.

Corroborando essa interpretação, vimos, a partir da definição apresentada por Bunge (1959/1963), que tanto a proposta de Merleau-Ponty quanto a proposta de Skinner não apresentam características definidoras do modelo causal de explicação. A partir das discussões e argumentos da análise desenvolvida, indicamos a adição de mais um item à relação de proposições metapsicológicas comuns entre a perspectiva fenomenológica-existencial europeia e a abordagem comportamentalista radical (Kvale \& Grenness, 1967): a crítica e superação do pensamento causal linear na explicação do comportamento.

Tanto na proposta fenomenológico-existencial merleau-pontyana, quanto no comportamentalismo radical skinneriano, encontramos a indi- 
cação da insuficiência da linearidade causal para abarcar a complexidade e fluidez do fenômeno comportamental, bem como a crítica à explicação causal como desvelamento do real, de algum mecanismo oculto, "não-aparente", ou "não-sensível". Desse modo, pode-se afirmar que, em ambas as abordagens, explicar não é encontrar as causas, mas sim descrever, para Merleau-Ponty, a estrutura do comportamento (Furlan, 2000); para Skinner, as contingências de reforçamento (Laurenti \& Lopes, 2009).

\section{Referências}

Abib, J. A. D. (1988). Comportamento, Subjetividade e Sentido. In Anais da XVIII Reunião Anual de Psicologia de Ribeirão Preto (pp. 419-427). Ribeirão Preto, SP: Sociedade de Psicologia de Ribeirão Preto.

Abib, J. A. D. (2004). O que é comportamentalismo? In M. Z. S. Brandão, F. C. S. Conte, F. S. Brandão, I. K. Ingberman, V. L. M. da Silva, \& S. M. Oliani (Eds.), Sobre comportamento e cognição: Vol. 13. Contingências e metacontingências: Contextos socioverbais e o comportamento do terapeuta (pp. 52-61). Santo André, SP: Esetec.

Bunge, M. (1963). Causality: The place of the causal principle in modern science. New York: The World Publishing Company. (Original work published 1959)

Carrara, K. (2005). Behaviorismo radical: Crítica e metacrítica. São Paulo, SP: Editora da Universidade Estadual Paulista "Júlio de Mesquita Filho".

Chiesa, M. (1994). Radical behaviorism: The philosophy and the science. Boston, MA: Authors Cooperative.

Day, W. F. (1969). Radical behaviorism in reconciliation with phenomenology. Journal of the Experimental Analysis of Behavior, 12, 315-328.

Furlan, R. (2000). A noção de "comportamento" na Filosofia de Merleau-Ponty. Estudos de Psicologia (Natal), 5(2), 383-400. doi:http://dx.doi. org/10.1590/S1413-294X2000000200005

Giorgi, A. (1975). Convergences and divergences between phenomenological psychology and behaviorism: A beginning dialogue. Behaviorism, 3(2), 200-212.
Hidalgo, M. (2017). Behaviorismo e fenomenologia? Notas sobre Merleau-Ponty e Skinner. In I. de O. Caminha \& A. J. Abath (Eds.), Merleau-Ponty e a psicologia (pp. 161-172). São Paulo, SP: LiberArs.

Hempel, C. (1965). Aspects of scientific explanation and other essays in the philosophy of science. New York: Free Press.

Japiassu, H. (1977). Introdução à epistemologia da psicologia (2. ed.). Rio de Janeiro, RJ: Imago.

Koffka, K. (1925). The Growth of the Mind. London: Kegan Paul, Trench, Trubner and Co.

Koffka, K. (1935). Principles of Gestalt Psychology. London: Kegan Paul, Tench, Trubner and Co.

Köhler, W. (1927). The mentality of apes. London: Routledge.

Köhler, W. (1930). Gestalt Psychology. London: G. Bell.

Kvale, S., \& Grenness, C. E. (1967). Skinner and Sartre: Toward a radical phenomenology of behaviorism? Review of Existential Psychology and Psychiatry, 7, 128-150.

Laurenti, C. (2009). Criatividade, liberdade e dignidade: Impactos do darwinismo no behaviorismo radical. Scientice Studia, 7(2), 251-269. doi:http:// dx.doi.org/10.1590/S1678-31662009000200006

Laurenti, C., \& Lopes, C. E. (2008). Uma explicação não-causal do comportamento no behaviorismo radical. Acta Comportamentalia, 16(3), 379397.

Laurenti, C., \& Lopes, C. E. (2009). Explicação e descrição no Behaviorismo Radical. Psicologia: Teoria e Pesquisa, 25(1), 129-136. doi:http:// dx.doi.org/10.1590/S0102-37722009000100015

Mach, E. (1959). The analysis of sensations (C. M. Williams, Trans.). New York: Dover. (Original work published 1886)

Merleau-Ponty, M. (2006). A estrutura do comportamento (M. V. M. de Aguiar, Trad.). São Paulo, SP: Martins Fontes. (Original publicado em 1942)

Merleau-Ponty, M. (1994). Fenomenologia da percepção (C. A. R. de Moura, Trad.). São Paulo, SP: Martins Fontes (Original publicado em 1945)

Pérez-Alvarez, M., \& Sass, L. A. (2008). Phenomenology and Behaviorism: A mutual readjust- 
ment. Philosophy, Psychiatry \& Psychology, 15(3), 199-210.

Pessotti, I. (1982). Movimento muscular e comportamento: Notas históricas. In B. Prado Jr. (Ed.), Filosofia e comportamento (pp. 11-32). São Paulo, SP: Brasiliense.

Sartre, J.-P. (1948). The emotions: Outline of a theory. New York: Philosophical Library. (Original work published 1939)

Sartre, J.-P. (1972). The Psychology of Imagination. London: Methuen \& Co. (Original work published 1940)

Skinner, B. F. (1957). Verbal behavior. New York: Prentice-Hall.

Skinner, B. F. (1961). The concept of the reflex in the description of behavior. In B. F. Skinner (Ed.), Cumulative record (pp. 319-346). New York: Appleton-Century-Crofts. (Original work published 1931)

Skinner, B. F. (1965). Science and Human Behavior. New York: The Free Press. (Original work published 1953)

Skinner, B. F. (1966). The behavior of organisms. New York: Appleton-Century. (Original work published 1938)

Skinner, B. F. (1969). Contingencies of reinforcement: A theoretical analysis. New York: Appleton-Century-Crofts.

Skinner, B. F. (1971). Beyond freedom and dignity. New York: Alfred A. Knopf.
Skinner, B. F. (1976). About behaviorism. New York: Vintage Books. (Original work published 1974)

Skinner, B. F. (1984). Selection by consequences. The Behavioral and Brain Sciences, 7(4), 477481. (Original work published 1981)

Skinner, B. F. (1985). Cognitive science and behaviourism. British Journal of Psychology, 76, 291301. doi:10.1111/j.2044-8295.1985.tb01953.x

Verissimo, D. (2012). A primazia do corpo próprio: Posição e crítica da função simbólica nos primeiros trabalhos de Merleau-Ponty. São Paulo, SP: Editora da Universidade Estadual Paulista "Júlio de Mesquita Filho".

Verissimo, D. S., \& Furlan, R. (2007). Entre a Filosofia e a Ciência: Merleau-Ponty e a Psicologia. Paideia (Ribeirão Preto), 17, 331-342. doi:http://dx.doi.org/10.1590/S0103$-863 \times 2007000300004$

Wann, T. W. (1964), Behaviorism and phenomenology: Contrasting bases for modern psychology. Chicago, IL: University of Chicago Press.

Recebido: 26/09/2016

$1^{a}$ revisão: $30 / 12 / 2016$ Aceite final: 08/02/2017

(C) O(s) autor(es), 2018. Acesso aberto. Este artigo está distribuído nos termos da Licença Internacional Creative Commons Atribuição 4.0 (http://creativecommons.org/licenses/by/4.0/), que permite o uso, distribuição e reprodução sem restrições em qualquer meio, desde que você dê crédito apropriado ao(s) autor(es) original(ais) e à fonte, fornecer um link para a licença Creative Commons e indicar se as alterações foram feitas. 